\title{
Machine learning models for identification of primary water concentrations in mantle pyroxene
}

\author{
HUAN CHEN, CHENG SU, YONG-QUAN TANG, J \\ ZHANGZHOU, SEN-SEN WU AND QUN-KE XIA
}

\author{
Zhejiang University
}

Presenting Author: huanchen@zju.edu.cn

The approach of estimating the $\mathrm{H}_{2} \mathrm{O}$ content of basaltic magmas via clinopyroxene (cpx) phenocrysts is a potentially effective way to glimpse the deep Earth water cycle. However, due to the wide diversity of substitution mechanisms for hydrogen $(\mathrm{H})$ in cpx and complex evolution of most magmas, it is difficult to ascertain using traditional geochemical methods whether or not $\mathrm{H}$ measured in cpx phenocrysts represents a primary signature that can ultimately inform the mantle water content.

The Support Vector Machine (SVM) is a powerful and mature machine learning method that can classify samples into two groups (classes) based on the analysis of high-dimensional datasets, meaning the SVM can simultaneously consider the complex relationships between $\mathrm{H}$ and major elemental compositions in cpx to distinguish samples that have experienced $\mathrm{H}$ diffusion from those that have not. In this study, we conducted machine learning on the major element compositions and $\mathrm{H}_{2} \mathrm{O}$ content of cpx phenocrysts collated from multiple studies that encompass localities around the globe (1869 data points in total). The data were divided into two groups: one group in which hydrogen diffusion is known not to have occurred (1461 data) and another group in which hydrogen diffusion has occurred (407 data). Using the support vector machine (SVM), we defined a classifier (overall accuracy $>90 \%$ ), that can separate pyroxenes that have undergone $\mathrm{H}$ diffusion or not. Our trained SVM model has broad implications for understanding the primary water content of magma and the variations in water content during magma evolution through the $\mathrm{H}$ in cpx, and the water cycle in the deep Earth by the basaltic magma. 